\title{
Límites a la exoneración de responsabilidad en el derecho internacional: amnistías, selección y priorización de casos en la jurisdicción nacional
}

Fecha de recepción: 14 de junio de 2012

Fecha de aceptación: 6 de octubre de 2012

Doi: dx.doi.org/10.12804/acdi7.2014.01

\section{Sebastián Machado Ramírez*}

Resumen: Mucho se ha discutido sobre las herramientas jurídicas con las cuales cuenta un Estado para asumir un proceso de justicia transicional. Tradicionalmente, la literatura ha estado discutiendo el contenido de los estándares de "verdad, justicia y reparación". No obstante, se le ha dedicado muy poca atención a las fuentes normativas que pueden limitar o permitir la exoneración parcial de responsabilidad en los procesos de justicia transicional. Esta exoneración puede ser parte de una política de selección y priorización de casos, lo cual puede estar vinculado a la concesión de amnistías o indultos parciales. El objetivo de este artículo es estudiar tres marcos regulatorios del derecho internacional: 1) el derecho internacional de los derechos humanos; 2) el derecho internacional humanitario; y 3) el derecho penal internacional.

\footnotetext{
* Abogado, Universidad de los Andes (2009), LL.M, Universidad de Cambridge (2011). Profesor de la maestría en derecho internacional, Universidad de los Andes. Quisiera agradecer a Paula Guerrero y Jorge Giraldo por sus comentarios al texto, aunque, naturalmente, cualquier error o imprecisión es totalmente mía. Todas las citas textuales en un idioma distinto al español han sido traducidas libremente. Correo electrónico: smachado@cantab.net

Para citar este artículo: Machado Ramírez, Sebastián (2014), "Límites a la exoneración de responsabilidad en el derecho internacional: amnistías, selección y priorización de casos en la jurisdicción nacional”. ACDI - Anuario Colombiano de Derecho Internacional vol. 7, pp. 13-37. doi: dx.doi.org/10.12804/acdi7.2014.01
} 
Un estudio cuidadoso demuestra que ningún instrumento internacional requiere que un Estado investigue o juzgue la totalidad de los casos relacionados con el conflicto. A grandes rasgos, el derecho internacional impide que se promulguen amnistías absolutas, pero permite que el Estado seleccione y priorice casos, sin castigar la exoneración parcial de responsabilidad de un grupo de involucrados.

Palabras clave: Corte Interamericana de Derechos Humanos, amnistías, obligación de investigación, aut dedere aut judicare, jurisdicciones complementarias.

\section{Limits on Exoneration from Responsibility in International Law: Amnesties, Selection and Priorization of Cases in National Jurisdiction}

Abstract. Much has been said about the legal tools that a State has to confront a process of transitional justice. Traditionally, international literature has discussed the content of the "truth, justice and reparation" standards. Notwithstanding, little attention has been paid to the legal sources that may limit or permit the partial preclusion of wrongfulness in transitional justice mechanisms. This preclusion of wrongfulness may be part of a prosecutorial policy of prioritization and selection of cases, which may be in turn linked to partial amnesties or pardons. The objective of this article is to study three regulatory frameworks in international law: 1) international human rights law; 2) international humanitarian law; and 3) international criminal law.

A close look reveals that no international instrument requires that a State investigates every case related to the armed conflict. In general terms, international law prohibits the adoption of blanket amnesties, but allows the State to select and prioritize its cases, without punishing the partial preclusion of wrongfulness of some of the perpetrators.

Key words: Interamerican Court of Human Rights, amnesties, duty to investigate, aut dedere aut judicare, complementary jurisdictions.

Limites à exoneração de responsabilidade no direito internacional: anistias, seleção e priorização de casos na jurisdição nacional

Resumo: Muito tem se discutido sobre as ferramentas jurídicas com as quais conta um Estado para assumir um processo de justiça transicional. 
Tradicionalmente, a literatura tem estado discutindo o conteúdo dos standards de "verdade, justiça e reparação". No entanto, tem se lhe dedicado muito pouca atenção às fontes normativas que podem limitar ou permitir a exoneração parcial de responsabilidade nos processos de justiça transicional. Esta exoneração pode ser parte de uma política de seleção e priorização de casos, o qual pode estar vinculado à concessão de anistias ou indultos parciais. O objetivo deste artigo é estudar três marcos regulatórios do direito internacional: 1) o direito internacional dos direitos humanos; 2) o direito internacional humanitário; e 3) o direito penal internacional.

Um estudo cuidadoso demonstra que nenhum instrumento internacional requere que um Estado Investigue ou julgue a totalidade dos casos relacionados com o conflito. A grandes traços o direito internacional impede que se promulguem anistias absolutas, mas permite que o Estado selecione e priorize casos, sem castigar a exoneração parcial de responsabilidade de um grupo de envolvidos

Palavras-chave: Corte Interamericana de Direitos Humanos, anistias, obrigação de pesquisa, aut dedere aut judicare, jurisdições complementárias.

\section{Introducción}

Una vez finalizado un conflicto armado, las sociedades afectadas suelen intentar reconciliar a sus víctimas y victimarios con el noble propósito de cicatrizar las heridas a nivel social, legal y político. Mucho se ha dicho sobre las herramientas existentes para lograr esta transición, hasta tal punto que se tiene toda una disciplina — la justicia transicional_ que estudia los distintos métodos para lograr la transición entre la guerra y la paz.

Para los abogados, las distintas discusiones suelen estar enfocadas en las posibilidades jurídicas que tiene un Estado para resolver un conflicto. Las limitaciones jurídicas de esta transición se han condensado en la famosa frase de "verdad, justicia y reparación"; tres componentes sin los cuales no es jurídicamente viable la reconciliación. Sin embargo, estos tres elementos deben ser ponderados en el posconflicto. En efecto, ese es su valor: el equilibrio entre tres principios que le otorga alguna deferencia al Estado para poder trascender el conflicto armado. Es claro que los miembros de un grupo armado irregular no se someterán voluntariamente al aparato judicial si no tienen incentivos para hacerlo. Es claro, también, que las víctimas de un conflicto no podrán superarlo sin la reparación adecuada. Y es cierto que la sociedad, 
en general, requiere de una dosis de verdad para poder sanar. No se trata entonces de una aplicación absoluta de la verdad, la justicia y la reparación, sino de una aplicación suficiente para sanar el trauma.

En este escenario, los Estados que se han visto inmersos en situaciones de posconflicto se han enfrentado con una disyuntiva. La cantidad de victimarios es tan alta, que la investigación y sanción de cada uno de ellos es frustrante para las víctimas, ya que no llega lo suficientemente rápido ni lo suficientemente eficiente. En algunos casos, el nivel de la violencia es de tal magnitud que la persecución penal total implica una judicialización de todo el aparato estatal, lo cual resulta no solo inviable, sino indeseable cuando el objetivo es la reconciliación. Por esta razón, algunos Estados han optado por priorizar sus investigaciones y seleccionar casos que consideran más importantes, con fundamento en criterios formales o informales. El caso paradigmático es el de Bosnia y Herzegovina por dos razones. La primera es la existencia de un tribunal penal internacional ad hoc con la capacidad de investigar y sancionar penalmente por hechos ocurridos en Bosnia y Herzegovina, lo cual generó, en la práctica, una jerarquía jurisdiccional que de manera obligatoria distinguía los casos más graves. La segunda es la existencia de criterios de selección y priorización por la jurisdicción bosnia, los cuales fueron adoptados por el Departamento Especial de Crímenes de Guerra de la Fiscalía General, y aplicados de manera exitosa. ${ }^{1}$ En otros casos de posconflicto como Serbia, Indonesia o Argentina no ha habido una política de priorización y selección de casos. ${ }^{2}$ En ninguno, sin embargo, se ha adoptado legalmente (y mucho menos constitucionalmente) una política de priorización y selección de casos, como se pretende hacer ahora en Colombia.

La discusión aquí contenida se enmarca de forma exclusiva en la exoneración parcial de responsabilidad, sea a través de selección o priorización de casos o las amnistías parciales como herramientas de la justicia transicional. Precisamente, el objetivo de este artículo es estudiar las limitaciones normativas que impone el derecho internacional para la selección de casos. Para estos efectos, primero se estudiará la regulación de los instrumentos internacionales de derechos humanos, después se hará lo mismo con los instrumentos de derecho internacional humanitario y por último se abordarán las jurisdicciones penales internacionales complementarias.

1 Morten, Bergsmo (ed.), Criteria for Prioritizing and Selecting Core International Crime Cases, Forum for International Criminal and Humantarian Law, International Peace Research Institute (2009), disponible en: http://www.fichl.org/publication-series/, p. 67.

2 Ibíd., pp. 69, 110, 113. 


\section{Limitaciones en el derecho internacional de los derechos humanos}

De los instrumentos internacionales de derechos humanos nos interesa principalmente la Convención Interamericana sobre Derechos Humanos ${ }^{3}$ (Pacto de San José, o en adelante, la "Convención Americana”), ya que es el tratado que le otorga jurisdicción a una corte internacional para adjudicar sobre violaciones de derechos humanos en Colombia. De esta manera podemos rescatar tres obligaciones específicas que limitan la manera como el Estado administra su justicia.

De forma general, el artículo 1(1) de la Convención Americana impone la obligación general del Estado de garantizar y respetar los derechos que se consagran en la Convención. ${ }^{4}$ Por su parte, el artículo 25 establece la obligación de protección judicial en los siguientes términos:

Artículo 25. Protección Judicial

1. Toda persona tiene derecho a un recurso sencillo y rápido o a cualquier otro recurso efectivo ante los jueces o tribunales competentes, que la ampare contra actos que violen sus derechos fundamentales reconocidos por la Constitución, la ley o la presente Convención, aun cuando tal violación sea cometida por personas que actúen en ejercicio de sus funciones oficiales.

2. Los Estados Partes se comprometen:

a) a garantizar que la autoridad competente prevista por el sistema legal del Estado decidirá sobre los derechos de toda persona que interponga tal recurso;

b) a desarrollar las posibilidades de recurso judicial, y

c) a garantizar el cumplimiento, por las autoridades competentes, de toda decisión en que se haya estimado procedente el recurso.

A primera vista, el artículo 1 y el artículo 25 de la Convención Americana parecerían imponer un deber de investigación absoluto para cualquier acto potencialmente violatorio del derecho internacional de los derechos

3 Colombia depositó su instrumento de ratificación a la Convención Americana el 31 de julio de 1973.

4 El artículo 1(1) dice de la siguiente manera: "1. Los Estados Partes en esta Convención se comprometen a respetar los derechos y libertades reconocidos en ella y a garantizar su libre y pleno ejercicio a toda persona que esté sujeta a su jurisdicción [...]”. 
humanos. Sin embargo, no se debe olvidar que, aunque estos instrumentos son aplicables a todas las situaciones de conflicto y posconflicto, sus obligaciones son susceptibles de ser ponderadas dependiendo del contexto, en particular en aquellos casos de atrocidades masivas.

Así lo confirma la jurisprudencia de la Corte Interamericana. En el caso de Maritza Urrutia v. Guatemala, por ejemplo, la Corte Interamericana tuvo la oportunidad de definir lo que entendía como impunidad contraria a la Convención Americana de la siguiente forma:

[I] impunidad es la falta, en conjunto, de investigación, persecución, captura, enjuiciamiento y condena de los responsables de las violaciones de los derechos protegidos por la Convención Americana, y que el Estado tiene la obligación de combatir tal situación por todos los medios legales disponibles ${ }^{5}$ (Resaltado fuera de texto).

Este mismo concepto se repite en toda la jurisprudencia de la Corte, en particular en el Caso de las Masacres de Ituango, ${ }^{6}$ Almonacid Arellano y otros, ${ }^{7}$ Masacre de Mapiripán ${ }^{8}$ y Comunidad Moiwana v. Surinam. ${ }^{9}$ Como se puede ver, se trata de una prohibición de la ausencia en conjunto de la investigación, captura, enjuiciamiento y condena. Esto hace que la noción de impunidad de la Corte no incluya necesariamente la ausencia de persecución penal en casos específicos.

La Corte Interamericana ha tenido amplias oportunidades de referirse a la obligación general de investigación y sanción en el contexto de amnistías latinoamericanas. En estas decisiones la Corte ha podido ahondar sobre la libertad que tiene un Estado para fijar su política criminal. Este contexto también le ha permitido referirse a la tensión que existe entre la búsqueda de la reconciliación y la obligación de someter a la justicia a los responsables

5 Corte Interamericana de Derechos Humanos, Caso Maritza Urrutia v. Guatemala, sentencia de fondo del 27 de noviembre de 2003, para. 126.

6 Corte Interamericana de Derechos Humanos, Caso de las Masacres de Ituango, sentencia de fondo del 1 de julio del 2006, para. 299.

7 Corte Interamericana de Derechos Humanos, Caso Almonacid Arellano y otros v. Chile, sentencia de fondo del 26 de septiembre de 2006, para. 111.

8 Corte Interamericana de Derechos Humanos, Caso de la Masacre de Mapiripán, sentencia de fondo del 15 de septiembre de 2005, para. 237.

9 Corte Interamericana de Derechos Humanos, Caso de la Comunidad Moiwana v. Surinam, sentencia de fondo del 15 de junio de 2005, para. 203. 
de violaciones de derechos humanos. El primer caso en ocuparse de estas leyes de amnistía fue el caso de Barrios Altos, donde la Corte se enfrentó a la exoneración de la responsabilidad de unos miembros del Ejército peruano acusados de cometer una masacre. En este caso, la Corte consideró:

[s]on inadmisibles las disposiciones de amnistía, las disposiciones de prescripción y el establecimiento de excluyentes de responsabilidad que pretendan impedir la investigación y sanción de los responsables de las violaciones graves de los derechos humanos tales como la tortura, las ejecuciones sumarias, extralegales o arbitrarias y las desapariciones forzadas, todas ellas prohibidas por contravenir derechos inderogables reconocidos por el Derecho Internacional de los Derechos Humanos ${ }^{10}$ (Resaltado fuera de texto).

En este mismo sentido se pronunció en el caso de Almonacid Arellano y otros v. Chile, donde la Corte debía analizar la exoneración de responsabilidad del régimen de Augusto Pinochet por el homicidio del peticionario. La Corte Interamericana se refirió a la obligación de investigar y sancionar comprendida dentro de la Convención Americana en términos muy específicos, encontrando que los Estados están obligados a perseguir y sancionar a los autores de crímenes internacionales y crímenes de lesa humanidad particularmente:

[1]a obligación conforme al derecho internacional de enjuiciar y, si se les declara culpables, castigar a los perpetradores de determinados crimenes internacionales, entre los que se cuentan los crímenes de lesa humanidad, se desprende de la obligación de garantía consagrada en el artículo 1.1 de la Convención Americana.

$[\ldots]$

Por las consideraciones anteriores, la Corte estima que los Estados no pueden sustraerse del deber de investigar, determinar y sancionar a los responsables de los crímenes de lesa humanidad aplicando leyes de amnistía u otro tipo de normativa interna. Consecuentemente, los crímenes

10 Corte Interamericana de Derechos Humanos, Caso Barrios Altos, sentencia de fondo del 14 de marzo de 2001, para. 41. 
de lesa humanidad son delitos por los que no se puede conceder amnistía ${ }^{11}$ (Resaltado fuera de texto).

En esta misma tónica se volvió a referir la Corte Interamericana a las exoneraciones de responsabilidad en el caso de Gelman v. Uruguay, donde tuvo la oportunidad de referirse a la "Ley de Caducidad" uruguaya que había impedido la investigación y juzgamiento de los presuntos responsables de la desaparición forzada de la peticionaria. Al respecto, la Corte expresó que:

[...] las leyes de amnistía, en casos de graves violaciones a los derechos humanos, son manifiestamente incompatibles con la letra y el espíritu del Pacto de San José $[\ldots] .^{12}$

Recientemente, sin embargo, la jurisprudencia ha empezado a contemplar de manera expresa la posible tensión entre el deber de investigación y juzgamiento y la necesidad de superar el conflicto armado de una sociedad. En el caso de Masacres de El Mozote y Lugares Aledaños v. El Salvador la Corte Interamericana tuvo la oportunidad de referirse por primera vez a una ley de amnistía expedida en el curso de un conflicto armado y con el objetivo de superarlo. En esta ocasión, consideró la Corte que:

[...] se colige que la lógica del proceso político entre las partes en conflicto, que llevó al cese de las hostilidades en El Salvador, imponía la obligación a cargo del Estado de investigar y sancionar a través de "la actuación ejemplarizante" de los tribunales de justicia ordinarios al menos las graves violaciones de derechos humanos que estableciera la Comisión de la Verdad, de modo tal que no quedaran impunes y se evitara su repetición ${ }^{13}$ (Resaltado fuera de texto).

Las implicaciones de esta consideración se pueden ver ilustradas por el voto concurrente del Juez García Sayán en el mismo caso, donde se pudo ahondar sobre el equilibrio entre la obligación de someter los responsables

11 Caso Almonacid Arellano y otros v. Chile, supra 7, para. 110-114.

12 Corte Interamericana de Derechos Humanos, Caso Gelman v. Uruguay, sentencia de fondo del 24 de febrero de 2011, para. 226.

13 Corte Interamericana de Derechos Humanos, Masacres de El Mozote y Lugares Aledaños $v$. El Salvador, sentencia de fondo del 25 de octubre de 2012, para. 288. 
a la justicia penal y la búsqueda de una paz negociada. Al respecto, dijo el Juez García Sayán:

[...] un conflicto armado y la solución negociada del mismo abre varios interrogantes y plantea enormes exigencias jurídicas y éticas en la búsqueda de la armonización entre justicia penal y paz negociada [...] Por ello, los Estados deben ponderar en este tipo de circunstancias el efecto de la justicia penal tanto sobre los derechos de las víctimas como sobre la necesidad de terminar el conflicto. ${ }^{14}$

Más adelante, continúa:

En este contexto, se pueden diseñar pautas específicas para el tratamiento de los responsables de las más graves violaciones abriendo el camino, por ejemplo, de priorizar los casos más graves como ruta de manejo de una problemática en la que podrían ser, en teoría, muchos miles los procesados y atender los casos de menor gravedad a través de otros mecanismos. $[\ldots]$

La reducción de penas, la concesión de penas alternativas, la reparación directa del perpetrador a la víctima, el reconocimiento público de responsabilidad, son otras vías que se pueden considerar. ${ }^{15}$

Los pasajes anteriores confirman que la obligación de investigación y sanción que se deriva de la Convención Americana no es absoluta y que el Estado puede escoger la focalización de sus esfuerzos para la persecución penal en algunas conductas específicas. En materia de amnistías o exoneraciones de responsabilidad penal, la Corte únicamente ha condenado los casos de exoneración total de actos que constituyen violaciones graves o masivas al derecho internacional. Esto sugiere que en el resto de conductas el Estado tendrá un margen de discrecionalidad más alto tanto para decidir que un caso no debe someterse a la justicia como para exonerar la responsabilidad de un acto que ya ha sido adjudicado. Esta conclusión la apoya la literatura especializada en el tema, donde se ha encontrado que la práctica

14 Corte Interamericana de Derechos Humanos, Masacres de El Mozote y Lugares Aledaños v. El Salvador, voto concurrente del Juez Diego García Sayán, sentencia de fondo del 25 de octubre de 2012, para. 26-27.

15 Ibíd., para. 29, 31. 
internacional de los Estados solo apunta a un deber de judicialización de los más responsables por los hechos más graves. ${ }^{16}$

Por su parte, la jurisprudencia del Tribunal Europeo de Derechos Humanos, aunque menos prolífera, está en sintonía con la posición de su homóloga interamericana. En el caso de Abdulsamet Yamat v. Turquía, el Tribunal consideró que la ausencia de investigación en un caso de presunta tortura por miembros de la Policía turca vulneraba el Convenio Europeo para la Protección de los Derechos Humanos y que las amnistías o prescripciones en los casos de tortura o maltrato contrariaban el derecho internacional. ${ }^{17}$ Por su parte, en el caso de Ould Dab v. Francia, haciendo referencia a la ley de amnistía en Mauritania, el Tribunal consideró que la prohibición de amnistías aplicaba específicamente a los casos de tortura en los siguientes términos:

$[\ldots]$ aunque es cierto que puede nacer un conflicto entre el deber de judicializar criminales, por un lado, y la determinación de un Estado de promover la reconciliación de un conflicto, por el otro [...] la prohibición de la tortura ocupa un lugar prominente en todos los instrumentos internacionales de derechos humanos. ${ }^{18}$

Teniendo en cuenta la noción de impunidad restringida que han manejado los estrados de derechos humanos, no es sorprendente que la Corte Interamericana haya encontrado que los Estados son responsables

16 Orentlicher, Diane, "Settling Accounts: The Duty to Prosecute Human Rights Violations of a Prior Regime", Yale Law Journal, 1991, 100, p. 2599; Olson, Laura M., "Provoking the Dragon on the Patio - Matters of Transitional Justice: Penal Repression v. Amnesties", International Review of the Red Cross, 2006, 88, pp. 284-285; Burke-White, William, "Reframing Impunity: Applying Liberal International Law Theory to an Analysis of Amnesty Legislation", Harvard International Law Journal, 2001, 42, p. 530.

17 European Court of Human Rights, Abdusalmet Yamat v. Turkey, judgment of 2 November 2004, para. 55. En este caso, la Corte consideró que “[...] where a State agent has been charged with crimes involving torture or ill-treatment, it is of the utmost importance for the purposes of an "effective remedy" that criminal proceedings and sentencing are not timebarred and that the granting of an amnesty or pardon should not be permissible".

18 European Court of Human Rights, Ould Dah v. France, judgment of 17 March 2009, para. 60. La traducción del inglés original es del autor: "[...] admittedly, the possibility of a conflict arising between, on the one hand, the need to prosecute criminals and, on the other hand, a country's determination to promote reconciliation in society cannot generally speaking be ruled out $[\ldots]$ however as the Court has already observed, the prohibition of torture occupies a prominent place in all international instruments relating to the protection of human rights $[\ldots] . "$. 
internacionalmente solo en casos de ausencia absoluta de investigación por violaciones dolosas del derecho a la vida y del derecho a la integridad personal. ${ }^{19}$ Esto indica que, aunque el derecho internacional no discrimina entre dolo y culpa para efectos de la responsabilidad internacional, la obligación de investigación y sanción sí puede matizarse dependiendo de la obligación vulnerada. Esto mismo se replica en las formas de reparación que ha ordenado la Corte, ya que solo ha exigido la investigación y persecución penal de los presuntos responsables cuando la violación de la obligación de otorgar un recurso judicial efectivo se debe a la inactividad absoluta por parte del Estado o a fallas procesales graves. ${ }^{20}$ Como se puede ver, y no obstante el lenguaje del artículo 25 de la Convención Americana, hasta la fecha ningún razonamiento de la Corte Interamericana ha indicado que la focalización de los recursos judiciales de un Estado, orientados por una política criminal de priorización y selección de casos, pueda ser contraria a las obligaciones que se derivan de la Convención americana.

Por fuera del ámbito judicial, los órganos especializados de derechos humanos también han sostenido una posición similar. En el caso de Rodríguez v. Uruguay, el Comité del Pacto Internacional de Derechos Civiles y Políticos estudió un caso de trato cruel, inhumano y degradante que había sido exonerado de responsabilidad mediante una amnistía legal. En este caso, consideró:

19 En los casos en los que no se demostró un acto doloso por parte de las autoridades, la Corte se abstuvo de ordenar una investigación o sanción de los hechos. Ver: Corte Interamericana de Derechos Humanos, Caso Lori Berenson Mejía v. Perú, sentencia de fondo del 25 de noviembre de 2004, para. 98-109; Corte Interamericana de Derechos Humanos, Caso Castillo Petruzzi otros v. Perú, sentencia de fondo del 30 de mayo de 1999, para. 192-198; Corte Interamericana de Derechos Humanos, Caso De la Cruz Flores v. Perú, sentencia de fondo del 18 de noviembre de 2004, para. 130; Corte Interamericana de Derechos Humanos, Caso Fermín Ramírez v. Guatemala, sentencia de fondo del 20 de junio de 2005, para. 117-119.

20 Corte Interamericana de Derechos Humanos, Caso de los "Niños de la Calle" (Villagrán Morales y otros) v. Guatemala, sentencia de fondo del 19 de noviembre de 1999, para. 250; Corte Interamericana de Derechos Humanos, Caso Cantoral Benavides v. Perú, sentencia de fondo del 18 de agosto de 2000, para. 188; Corte Interamericana de Derechos Humanos, Caso Tibi v. Ecuador, sentencia de fondo del 7 de septiembre de 2004, para. 255; Corte Interamericana de Derechos Humanos, Caso del Caracazo v. Venezuela, sentencia de fondo del 29 de agosto de 2002, para. 116; Corte Interamericana de Derechos Humanos, Caso Bulacio v. Argentina, sentencia de fondo del 18 de septiembre de 2003, para. 113-116; Corte Interamericana de Derechos Humanos, Caso 19 Comerciantes v. Colombia, sentencia de fondo del 5 de julio de 2004, para. 256; Corte Interamericana de Derechos Humanos, Caso Masacre Plan de Sánchez v. Guatemala, sentencia de fondo del 19 de noviembre 2004, para. 94. 
El Comité reafirma su posición bajo la cual las amnistias por violaciones masivas de derechos humanos [...] son incompatibles con las obligaciones de un Estado parte bajo el Pacto. El Comité nota con gran preocupación que la adopción de esta ley efectivamente excluye en un número de casos la posibilidad de investigar abusos de derechos humanos y por lo tanto previene que el Estado parte cumpla con su responsabilidad de proveer un remedio efectivo a las víctimas de dichos abusos ${ }^{21}$ (Resaltado fuera de texto).

Toda la jurisprudencia de órganos judiciales y no judiciales especializados en derechos humanos demuestra que solo se ha encontrado responsable internacionalmente a los Estados que exoneran por completo a los responsables de violaciones masivas y graves de derechos humanos. De la misma manera, se ha encontrado que la inactividad absoluta o las fallas estructurales en las investigaciones vulneran los instrumentos internacionales. Esto permite concluir que la concentración de recursos en algunos casos específicos, o la decisión de no someter actos delictivos a la justicia no implica, en sí mismo, una violación de los estándares internacionales. Los límites se encuentran en aquellas graves o masivas violaciones de derechos humanos. En estos casos no se puede optar por algo distinto a la investigación y, en el caso de encontrar responsabilidad penal, la sanción. Es importante resaltar que la selección o priorización de un caso tiene implicaciones penales distintas a las amnistías, ya que implican la ausencia de investigación sin afectar la responsabilidad penal de las personas. Las amnistías, sin embargo, sí implican la exoneración de responsabilidad por un hecho ilícito. Lo anterior implica que una selección objetiva de casos que comprendan las violaciones graves de derechos humanos no riñe con las obligaciones internacionales del Estado en los instrumentos de derechos humanos.

\section{Limitaciones en derecho internacional humanitario}

El derecho internacional humanitario, para efectos prácticos de este artículo, está comprendido por los Convenios de Ginebra ${ }^{22}$ y sus Protocolos

21 Comité del Pacto Internacional de Derechos Civiles y Políticos, Rodríguez v. Uruguay, comunicación 322/1988, 19 de julio 1994, para. 12.4.

22 Los Convenios de Ginebra son cuatro tratados distintos que regulan la conducción de hostilidades en situaciones de conflicto armado, a saber: el Convenio de Ginebra para Aliviar la Suerte que Corren los Heridos y los Enfermos de las Fuerzas Armadas en Campaña, de 12 de agosto de 1949, 75 C.T.N.U. 31 (en adelante, "I Convenio de Ginebra"), el Convenio 
Adicionales. ${ }^{23}$ Los conflictos armados de carácter internacional están regulados por todos los Convenios de Ginebra, a excepción del artículo 3 común a los mismos, y por el Protocolo Adicional I. Por contraste, los conflictos armados de carácter no-internacional están regulados por el artículo 3 común a los Convenios de Ginebra y por el Protocolo Adicional II.

La única obligación de investigación y enjuiciamiento que se deriva del derecho internacional humanitario es de carácter convencional, ya que se encuentra explícitamente consagrada en los Convenios de Ginebra. Esta obligación hace parta del llamado "régimen de infracciones graves", donde los mismos Convenios adoptan medidas especiales para las violaciones de algunas obligaciones en particular y se encuentra tipificada en el artículo 49(2) del I Convenio de Ginebra, el artículo 50(2) del II Convenio de Ginebra, el artículo 129(2) del III Convenio de Ginebra y el artículo 146(2) del IV Convenio de Ginebra de la siguiente forma:

Cada una de las Partes Contratantes tendrá la obligación de buscar a las personas acusadas de haber cometido, u ordenado cometer, una cualquiera de las infracciones graves, y deberá hacerlas comparecer ante los propios tribunales, sea cual fuere su nacionalidad. Podrá también, si lo prefiere, y según las disposiciones previstas en la propia legislación, entregarlas para que sean juzgadas por otra Parte Contratante interesada, si ésta ha formulado contra ellas cargos suficientes.

Todo el "régimen de infracciones graves" existe únicamente para las violaciones de los Convenios de Ginebra distintos al artículo común 3, por lo que es aplicable de manera convencional únicamente a los conflictos

de Ginebra para Aliviar la Suerte que Corren los Heridos, los Enfermos y los Náufragos de las Fuerzas Armadas en el Mar, de 12 de agosto de 1949, 75 C.T.N.U 85 (en adelante, el "II Convenio de Ginebra"); el Convenio de Ginebra Relativo al Trato Debido a los Prisioneros de Guerra, de 12 de agosto de 1949, 75 C.T.N.U. 135 (en adelante, el "III Convenio de Ginebra") y el Convenio de Ginebra Relativo a la Protección Debida a las Personas Civiles en Tiempo de Guerra, de 12 de agosto de 1949, 75 C.T.N.U. 287 (en adelante, "IV Convenio de Ginebra", y colectivamente los "Convenios de Ginebra).

23 Protocolo Adicional a los Convenios de Ginebra del 12 de agosto de 1949 Relativo a la Protección de las Víctimas de los Conflictos Armados Internacionales, 8 de junio de 1977, 1125 C.T.N.U. 3 y el Protocolo Adicional a los Convenios de Ginebra del 12 de agosto de 1949 Relativo a la Protección de las Víctimas de los Conflictos Armados Sin Carácter Internacional, 8 de junio de 1977, 1125 C.T.N.U. 609 (en adelante, "Protocolo Adicional I" y "Protocolo Adicional II", respectivamente). 
armados internacionales. Esto significa que con fundamento en una norma convencional, la obligación de enjuiciar a los responsables de violaciones de DIH no es aplicable a las violaciones ocurridas en curso de los conflictos armados de carácter no-internacional.

Lo anterior significa que la obligación de investigar y sancionar a los presuntos responsables de violaciones al DIH en conflictos armados nointernacionales solo podría venir del derecho consuetudinario. En este sentido se pronunció el Tribunal Penal Internacional para la antigua Yugoslavia en la decisión de jurisdicción del Caso Tadic, al considerar que el régimen de infracciones graves al derecho internacional humanitario estaba gradualmente materializándose en derecho consuetudinario aplicable a los conflictos armados no internacionales. ${ }^{24}$ De la misma manera, el estudio de derecho internacional consuetudinario realizado por el Comité Internacional de la Cruz Roja ha concluido que el régimen de infracciones graves es igualmente aplicable a los actos cometido en conflictos armados no internacionales. ${ }^{25}$

Sin embargo, tanto la doctrina como la jurisprudencia han llegado a conclusiones distintas a las que sugieren Tadic y el Comité Internacional de la Cruz Roja. Por su parte, la literatura ha demostrado que para las violaciones de derecho internacional humanitario aplicables al conflicto armado no internacional existe un deber general, mas no una obligación de investigación. ${ }^{26}$ Esta conclusión también es apoyada por la Comisión de Derecho Internacional de la ONU, cuya relatoría especial sobre el tema ha concluido que el principio de aut dedere aut judicare no tiene un estatus consuetudinario. ${ }^{27}$ Finalmente, y no obstante que la Corte Internacional de Justicia no se

24 International Criminal Tribunal for the Former Yugoslavia, Decision on the Defense Motion for Interlocutory Appeal on Jurisdiction (IT-94-1), Appeals Chamber, 2 October 1995, para. 83.

25 Henckaerts, Jean Marie y Doswald-Beck, Louise, Customary International Humanitarian Law, Cambridge University Press, Cambridge, 2005, p. 607.

26 Ver: Kress, Claus, "War Crimes Committed in Non-International Armed Conflicts and the Emerging System of International Criminal Justice", Israel Yearbook on Human Rights, 2000, p. 104.

27 En reacción al "reporte preliminar", donde el Relator Especial sugería que la obligación de aut dedere aut judicare podía ser consuetudinaria en algunos casos, los Estados parte de la Asamblea General tomaron una posición muy fuerte en contra de esta posibilidad. En el último informe presentado (2008), el Relator Especial concluyó que los Estados habían tomado una "aproximación más relajada", no obstante que consideró que era una obligación convencional exclusivamente. Ver: Zdzislaw Galicki (Sp. Rap.) "Third Report on the Obligation to Extradite or Prosecute (aut dedere aut judicare)", International Law Commission A/CN.4/603, 10 June 2008, para. 25. 
refirió al estatus consuetudinario de esta norma en su reciente sentencia de Questions Related to the Obligation to Prosecute or Extradite (Bélgica v. Senegal), ya que consideró que la disputa solo podía adjudicarse con fundamento en la Convención contra la Tortura y otros Tratos o Penas Crueles, Inhumanas y Degradantes de $1984,{ }^{28}$ el único juez de que consideró que dicha pregunta debía ser resuelta por la Corte también expresó que la obligación de juzgamiento o extradición no hacía parte del derecho internacional consuetudinario, inclusive para casos de tortura. ${ }^{29}$

De cualquier manera, hay que tener en cuenta que la obligación de investigación y sanción en el derecho internacional humanitario es de medio y no de resultado. Esto significa que, inclusive si existiera un "régimen de infracciones graves" para los conflictos armados no internacionales, las potenciales violaciones del DIH obligarían a los Estados territoriales a someter el asunto a la judicialización, así el resultado fuera un archivo por falta de méritos. ${ }^{30}$

Adicionalmente, un sector de la literatura defiende la compatibilidad de la obligación de aut dedere aut judicare con los procesos de justicia transicional donde existan exoneraciones parciales de responsabilidad ${ }^{31}$ y no se puede olvidar que el artículo 6(5) del Protocolo Adicional II a los Convenios de Ginebra exhorta a los Estados a conceder amnistías una vez han culminado los conflictos armados no-internacionales en los siguientes términos:

[a] la cesación de las hostilidades, las autoridades en el poder procurarán conceder la amnistía más amplia posible a las personas que hayan tomado parte en el conflicto armado o que se encuentren privadas de libertad, internadas o detenidas por motivos relacionados con el conflicto armado. ${ }^{32}$

28 International Court of Justice, Questions Relating to the Obligation to Prosecute or Extradite (Belgium v. Senegal), merits judgment, 20 July 2012, para. 55.

29 International Court of Justice, Questions Relating to the Obligation to Prosecute or Extradite (Belgium v. Senegal), Separate Opinion of Judge Abraham, 20 July 2012, para. 21.

30 Kress, Claus, "Reflections on the Iudicare Limb of the Grave Breaches Regime", 7 Journal of International Criminal Justice, 2009, 7, p. 801.

31 Grover, Leena y Kress, Claus, "International Criminal Law Restraints in Peace Talks to End Armed Conflicts of a Non-International Character", en Bergsmo, M., Kalmanovitz, P., Law in Peace Negotiations, FICHL Publications Series, Oslo, 2009, pp. 29-53.

32 Protocolo Adicional II, supra 19, art. 6(5). 
Este mandato jurídico ha sido interpretado como una invitación a la conmutación de penas y la exoneración de responsabilidades penales por los hechos ocurridos en el conflicto armado doméstico, siempre de los límites que imponga el derecho internacional. No obstante que esta norma ilustra la intención del DIH de conciliar la tensión inherente entre la obligación de investigación y la necesidad de superar un conflicto armado, no puede interpretarse como una obligación de eliminar la responsabilidad penal por la comisión de crímenes de guerra. ${ }^{33}$

De todo lo anterior es posible concluir que el derecho internacional humanitario también incluye una obligación de investigación y sanción por la comisión de algunas conductas violatorias del mismo. Esta obligación se encuentra convencionalmente aplicable a los conflictos armados internacionales, y su aplicación consuetudinaria a los conflictos armados no internacionales es muy cuestionable. Las conductas que están sometidas a la investigación y juzgamiento, según los Convenios de Ginebra son, a grandes rasgos, el homicidio intencional, la tortura o los tratos inhumanos, incluidos los experimentos biológicos; el hecho de causar deliberadamente grandes sufrimientos o de atentar gravemente contra la integridad física o la salud y la destrucción y la apropiación de bienes no justificadas por necesidades militares y efectuadas a gran escala ilícita y arbitrariamente. ${ }^{34}$ Como en el derecho internacional de los derechos humanos, vemos que el DiH deja un margen de discrecionalidad al Estado para que incluya dentro de su política criminal posconflicto alguna forma de exoneración de responsabilidad o de selectividad en los casos.

33 No obstante que el Protocolo Adicional II no ha sido objeto de comentarios oficiales por parte del Comité Internacional de la Cruz Roja, el jefe de la división jurídica del organismo le expresó, mediante una comunicación escrita el 15 de abril de 1997 al Fiscal del Tribunal Penal para la antigua Yugoslavia, que "los trabajos preparatorios [del artículo 6(5)] indican que esta norma apunta a la promoción de las amnistías [...] para aquellos detenidos o castigados por el mero hecho de haber participado en las hostilidades. No apunta a una amnistía para aquellos que han violado el derecho internacional humanitario". Esta comunicación está citada en: Cassel, Douglas, "Lessons from the Americas: Guidelines for International Response to Amnesties for Atrocities", Law \& Contemporary Problems, 1996, 59 p. 218.

34 Estos son los elementos expresamente consignados en el 49(2) del I Convenio de Ginebra, aunque varían levemente dependiendo del instrumento. 


\section{Activación de jurisdicción penal internacional}

Basta con dar una mirada a los estatutos de algunos de los tribunales penales internacionales para observar que su jurisdicción está encaminada a juzgar únicamente a los máximos responsables de los crímenes. Por ejemplo, el Estatuto del Tribunal Penal Internacional para la antigua Yugoslavia determinó que su jurisdicción estaba dirigida a castigar penalmente a los líderes del conflicto armado responsables de violaciones al derecho internacional humanitario. ${ }^{35}$ Lo mismo se observa en la jurisdicción de las Cortes Extraordinarias de Camboya, destinadas a perseguir penalmente a los altos funcionarios y líderes que por tal tienen mayor responsabilidad. ${ }^{36}$ Caso parecido es el de Estatuto de la Corte Especial para Sierra Leona, establecida para juzgar a los máximos responsables por la comisión de delitos de su jurisdicción.

En la actualidad, el panorama es algo distinto ya que los tribunales ad hoc son algo del pasado y contamos ahora con una Corte Penal Internacional permanente. Esta jurisdicción permanente es tal vez la que más miedo infunde a un Estado que pretende priorizar y seleccionar casos, ya que uno de los principios rectores de la Corte Penal Internacional (en adelante, la “CPI") es el de la jurisdicción complementaria. ${ }^{37} \mathrm{El}$ artículo 17 del Estatuto de Roma de la CPI establece unos límites a la admisibilidad de casos ante la Corte de la siguiente manera:

\section{Artículo 17}

Cuestiones de admisibilidad

1. La Corte teniendo en cuenta el décimo párrafo del preámbulo y el artículo 1, resolverá la inadmisibilidad de un asunto cuando:

35 Cassese, Antonio, “The ICTY: A Living and Vital Reality”, Journal of International Criminal Justice, 2004, 2, pp. 585, 587.

36 El acuerdo para el establecimiento de este tribunal híbrido se encuentra anexo a la resolución de la Asamblea General de Naciones Unidas 57/228. El artículo 2 del mismo dispone, en el inglés original: "The present Agreement further recognizes that the Extraordinary Chambers have personal jurisdiction over senior leaders of Democratic Kampuchea and those who were most responsible for the crimes referred to in Article 1 of the Agreement".

37 Esto es, en principio, el fundamento de la priorización de casos implícita en los estatutos de los tribunales ad hoc. A fin de cuentas, la existencia de los tribunales obedecía fundamentalmente a la incapacidad o falta de iniciativa para investigar y sancionar a los responsables en situaciones históricas específicas. 
a) El asunto sea objeto de una investigación o enjuiciamiento por un Estado que tenga jurisdicción sobre él salvo que éste no esté dispuesto a llevar a cabo la investigación o el enjuiciamiento o no pueda realmente hacerlo;

b) El asunto haya sido objeto de investigación por un Estado que tenga jurisdicción sobre él y éste haya decidido no incoar acción penal contra la persona de que se trate, salvo que la decisión haya obedecido a que no esté dispuesto a llevar a cabo el enjuiciamiento o no pueda realmente hacerlo;

c) La persona de que se trate haya sido ya enjuiciada por la conducta a que se refiere la denuncia, y la Corte no pueda adelantar el juicio con arreglo a lo dispuesto en el párrafo 3 del artículo 20;

d) El asunto no sea de gravedad suficiente para justificar la adopción de otras medidas por la Corte.

Lo anterior implica, en pocas palabras, que la CPI activa su jurisdicción únicamente cuando el Estado no quiera o no pueda investigar y sancionar a las personas que hayan cometido delitos bajo la jurisdicción del Estatuto de Roma. Es preciso recordar que la jurisdicción complementaria de la CPI se limita a la persecución de los crímenes más graves. De hecho, el artículo 1 del Estatuto de Roma dispone que la misma "estará facultada para ejercer su jurisdicción sobre personas respecto de los crímenes más graves de trascendencia internacional". Por lo tanto, sobra decir que un delito común, es decir, aquel que no es de envergadura internacional, no tiene la capacidad de activar la jurisdicción complementaria de esa corte internacional. En consecuencia, el primer elemento que se debe considerar con respecto a la jurisdicción de la CPI es que puede ejercerse únicamente con respecto a los máximos responsables de los crímenes más graves.

Sin embargo, en un caso de justicia transicional, donde se pretende superar un trauma masivo de la sociedad, se ajusta el estándar de justicia para permitir que solo algunos de los casos tengan sanciones graves y, bajo algunas circunstancias, que incentiven a los beligerantes a abandonar el conflicto. La premisa fundamental es que no se administrará justicia de la misma manera que se hace en un momento de paz, lo que conlleva una graduación de las penas de los victimarios. Naturalmente, esto deja por fuera del proceso a algunas personas que participaron en el conflicto y que, en estricto sentido, no son sometidos al peso de la ley. Ello genera un conflicto jurisdiccional, ya que la justicia doméstica dejará de sancionar unos casos que según el Estatuto de Roma deben ser juzgados. 
Debido a que desde sus inicios se temió que la CPI pudiera entorpecer procesos de justicia transicional y reconciliación adelantados por los Estados, se ha procurado aproximar figuras de justicia disimiles a las tradicionales, en especial aquellas que incluyen amnistías parciales, con el cometido principal de la CPI: la lucha contra la impunidad. ${ }^{38}$ Justamente por eso un amplio sector de la doctrina afirma que la exoneración parcial de responsabilidad durante procesos de justicia transicional legítimos no contraviene las disposiciones del Estatuto de Roma. ${ }^{39}$

Por lo tanto, procesos de paz que apelen a comisiones de verdad pero que a su vez concedan amnistías condicionadas para aquellos que no sean los máximos responsables de los crímenes más graves resultan acordes con el Estatuto de la Corte Penal Internacional. ${ }^{40}$ En efecto, el artículo 53(1)(c) del Estatuto de Roma permite que el Fiscal archive investigaciones siempre que existan "razones sustanciales para creer que, aun teniendo en cuenta la gravedad del crimen y los intereses de las víctimas, una investigación no redundaría en interés de la justicia”. Por lo tanto, de alguna manera, el Estatuto de la CPI reconoce que en ciertos casos resulta legítima la aplicación de sistemas de justiciabilidad más laxos. Sin embargo, en caso de que el Fiscal tome esta decisión, la Corte, en su control jurisdiccional, deberá asegurarse de que realmente se trate de una decisión legítima. ${ }^{41}$

De igual forma, el artículo 17 (1)(b) del Estatuto puede interpretarse de tal manera que reconozca procesos de justicia transicional como procedimientos judiciales suficientes que, de hecho, permiten que no se justifique el ejercicio de la jurisdicción complementaria de la Corte. Sin embargo, para que este sea el caso, el Estado deberá probar que llevó a cabo investigaciones juiciosas que, a pesar de no resultar en una acción penal sancionatoria,

38 Villa-Vicencio, Charles, "Why Perpetrators Should Not Always Be Prosecuted: Where the International Criminal Court and Truth Commissions Meet", Emory Law Journal, 2000, 49, p. 205.

39 Ver, por ejemplo, Scharf, Michael, "The Amnesty Exception to the Jurisdiction of the International Criminal Court”, Cornell International Law Journal, 1997, 32, p. 507; Arsanjani, Mahnoush, "The International Criminal Court and National Amnesty Laws", ASIL Proceedings, 1995, p. 6; Zappala, Salvatore, Human Rights in International Criminal Proceedings, Oxford University Press, Oxford, 2003, pp. 43-44.

40 Robinson, Darryl, "Serving the Interests of Justice: Amnesties, Truth Commissions, and the International Criminal Court", European Journal of International Law, 2003, 14, p. 483.

41 Dukic, Drazan, "Transitional Justice and the International Criminal Court - 'In the Interest of Justice?", International Review of the Red Cross, 2007, 89, p. 715. 
tal decisión se dio con bases legítimas. Esto incluye que se demuestre que el accionar del Estado no obedezca a razones de incapacidad o indisposición de brindar justicia.

Una tercera posibilidad se deriva de la relación política que existe entre el Consejo de Seguridad y la Corte Penal Internacional. Bajo el Estatuto de Roma, el Consejo de Seguridad cuenta con ciertas prerrogativas donde se considera que las decisiones judiciales de la Corte pueden tener una injerencia en la paz y seguridad internacional. Por ello, por ejemplo, el Consejo de Seguridad puede impedir que el Fiscal de la Corte inicie una investigación por el delito de agresión. De la misma manera, el Consejo puede adoptar una resolución bajo el Capítulo VII de la Carta de Naciones Unidas donde puede detener cualquier investigación que haya iniciado el Fiscal cuando dicha investigación pueda atentar contra la paz y seguridad internacional. ${ }^{42}$

Para resumir, el ejercicio penal a partir del principio de priorización, esto es, concentrando la acción penal en los máximos responsables y por los crímenes más graves, encuentra sustento en la práctica de los tribunales penales internacionales. Por lo tanto, aquellos que hayan cometido crímenes que no son de transcendencia internacional y que además se encuentren entre los escalafones inferiores de la organización criminal no podrán, en ningún caso, ser objeto de la jurisdicción complementaria de la Corte Penal Internacional. De igual forma, los sistemas alternativos de justicia que consistan en comisiones de verdad y amnistías condicionadas para victimarios de menor jerarquía son compatibles con el Estatuto de Roma, siempre que se investigue y juzgue a los máximos responsables. ${ }^{43}$ Esto es porque el Estatuto confiere cierto margen de discrecionalidad al Estado para que haga de ajuste sus procedimientos domésticos a unos de justicia transicional que de cualquier manera podrían satisfacer el estándar de justicia del Estatuto de Roma. De la misma manera, el Estatuto autoriza al Fiscal para que, en interés de la justicia, suspenda o archive investigaciones. Finalmente, y de

42 El Artículo 16 versa de la siguiente manera: "En caso de que el Consejo de Seguridad, de conformidad con una resolución aprobada con arreglo a lo dispuesto en el Capítulo VII de la Carta de las Naciones Unidas, pida a la Corte que no inicie o que suspenda por un plazo de doce meses la investigación o el enjuiciamiento que haya iniciado, la Corte procederá a esa suspensión; la petición podrá ser renovada por el Consejo de Seguridad en las mismas condiciones".

43 Robinson, Darryl, "Serving the Interests of Justice: Amnesties, Truth Commissions, and the International Criminal Court", European Journal of International Law, 2003, 14, p. 483. 
cualquier manera, el Consejo de Seguridad puede intervenir en el proceso judicial para garantizar que los Estados busquen la reconciliación.

Por lo tanto, el derecho penal internacional concede cierto margen de libertad a los Estados para decidir cuáles crímenes cometidos en conflicto sancionará penalmente. Así las cosas, esta regulación es similar a la establecida por el derecho internacional de los derechos humanos, en la cual no se encuentra disposición alguna que impida que los Estados ejerzan tal discrecionalidad, imponiendo como único límite la prohibición de conceder amnistías generales y absolutas.

\section{Conclusiones}

Como es manifiesto para este punto, el derecho internacional no prohíbe la exoneración parcial de responsabilidad en las jurisdicciones domésticas. Todo lo contrario, los distintos instrumentos de derecho internacional de los derechos humanos, derecho internacional humanitario y derecho penal internacional están diseñados para reconocerle un margen de deferencia al Estado en su política criminal cuando pretende trascender un conflicto armado, imponiendo unas limitaciones generales usualmente enmarcadas en la gravedad de los delitos cometidos.

En los instrumentos de derechos humanos no existe una prohibición generalizada de la aplicación de mecanismos de justicia transicional que impliquen exoneraciones parciales de responsabilidad. La jurisprudencia de derechos humanos muestra solo un fuerte rechazo hacia las leyes de "autoamnistía" de carácter absoluto, y nunca se ha encontrado que un Estado es internacionalmente responsable por la implementación de una política criminal que exonere algunos casos, prevea penas alternativas, o cualquier otro mecanismo híbrido, siempre y cuando no haya una impunidad generalizada o se exoneren los casos de violaciones graves de derechos humanos. La noción de impunidad adoptada por la Corte Interamericana de Derechos Humanos, a su vez, reprocha únicamente las fallas estructurales en la investigación y sanción, y no exige un juzgamiento exhaustivo o total.

El derecho internacional humanitario, por su parte, está fragmentado en la regulación de los conflictos armados internacionales y los conflictos armados no internacionales. Por un lado, la obligación de investigación o entrega de los presuntos responsables vincula de manera convencional a los Estados únicamente en los casos de conflictos armados internacionales. Si bien existe la tendencia a aplicar el régimen de las infracciones graves a los conflictos armados no internacionales de manera consuetudinaria, en 
la actualidad no existe un consenso sobre el tema. De cualquier manera, la obligación se satisface con la mera investigación del ente competente, sin necesidad de acusar o condenar al presunto responsable y se limita de manera exclusiva a las violaciones graves de derecho internacional humanitario.

Finalmente, el derecho penal internacional plantea el problema de modo más complejo, toda vez que es el único ámbito donde la jurisdicción nacional se puede ver remplazada por la justicia internacional. Sin embargo, la jurisdicción penal internacional se extiende solo a los individuos más responsables por los crímenes más graves y excluye a cualquier otro actor de un conflicto. Adicionalmente, el Estatuto de Roma de la Corte Penal Internacional tiene las salvaguardias procedimentales necesarias para frenar una potencial investigación cuando el Estado se encuentra en un genuino intento de administración de justicia transicional, así esto incluya exoneraciones parciales de responsabilidad o implementación de mecanismos híbridos de justicia.

\section{Referencias bibliográficas}

\section{Casos}

Corte Interamericana de Derechos Humanos, Caso Fermin Ramirez v. Guatemala, sentencia de fondo del 20 de junio de 2005.

Comité del Pacto Internacional de Derechos Civiles y Políticos, Rodríguez v. Uruguay, comunicación 322/1988, 19 de julio de 1994.

Corte Interamericana de Derechos Humanos, Caso 19 Comerciantes v. Colombia, sentencia de fondo del 5 de julio de 2004.

Corte Interamericana de Derechos Humanos, Caso Almonacid Arellano y otros v. Chile, sentencia de fondo del 26 de septiembre de 2006.

Corte Interamericana de Derechos Humanos, Caso Barrios Altos, sentencia de fondo del 14 de marzo de 2001.

Corte Interamericana de Derechos Humanos, Caso Bulacio v. Argentina, sentencia de fondo del 18 de septiembre de 2003.

Corte Interamericana de Derechos Humanos, Caso Cantoral Benavides v. Perú, sentencia de fondo del 18 de agosto de 2000

Corte Interamericana de Derechos Humanos, Caso Castillo Petruzziy otros v. Perú, sentencia de fondo del 30 de mayo de 1999.

Corte Interamericana de Derechos Humanos, Caso de la Comunidad Moiwana v. Surinam, sentencia de fondo del 15 de junio de 2005. 
Corte Interamericana de Derechos Humanos, Caso De la Cruz Flores v. Perú, sentencia de fondo del 18 de noviembre de 2004.

Corte Interamericana de Derechos Humanos, Caso de la Masacre de Mapiripán, sentencia de fondo del 15 de septiembre de 2005.

Corte Interamericana de Derechos Humanos, Caso de las Masacres de Ituango, sentencia de fondo del 1 de julio del 2006.

Corte Interamericana de Derechos Humanos, Caso de los "Niños de la Calle" (Villagrán Morales y otros) v. Guatemala, sentencia de fondo del 19 de noviembre de 1999.

Corte Interamericana de Derechos Humanos, Caso del Caracazo v. Venezuela, sentencia de fondo del 29 de agosto de 2002.

Corte Interamericana de Derechos Humanos, Caso Lori Berenson Mejía v. Perú, sentencia de fondo del 25 de noviembre de 2004.

Corte Interamericana de Derechos Humanos, Caso Maritza Urrutia v. Guatermala, sentencia de fondo del 27 del noviembre de 2003.

Corte Interamericana de Derechos Humanos, Caso Masacre Plan de Sánchez.v. Guatemala, sentencia de fondo del 19 de noviembre 2004.

Corte Interamericana de Derechos Humanos, Caso Tibi v. Ecuador, sentencia de fondo del 7 de septiembre de 2004.

European Court of Human Rights, Abdusalmet Yamat v. Turkey, judgment of 2 November 2004

European Court of Human Rights, Ould Dah v. France, judgment of 17 March 2009.

International Court of Justice, Questions Relating to the Obligation to Prosecute or Extradite (Belgium v. Senegal), merits judgment of 20 July 2012.

International Court of Justice, Questions Relating to the Obligation to Prosecute or Extradite (Belgium v. Senegal), Separate Opinion of Judge Abraham, 20 July 2012.

International Criminal Tribunal for the Former Yugoslavia, Decision on the Defense Motion for Interlocutory Appeal on Juridiction (IT-94-1), Appeals Chamber, 2 October 1995.

\section{Libros}

Grover, Leena y Kress, Claus, "International Criminal Law Restraints in Peace Talks to End Armed Conflicts of a Non-International Character", en Bergsmo, M, Kalmanovitz, P, Law in Peace Negotiations, FICHL Publications Series, Oslo, 2009, pp. 29-53. 
Henckaerts Jean Marie y Doswald-Beck, Louise, Customary International Humanitarian Law, Cambridge University Press, Cambridge, 2005.

Zappala, Salvatore, Human Rights in International Criminal Proceedings, Oxford University Press, Oxford, 2003.

\section{Otras autoridades}

Morten Bergsmo (ed.), Criteria for Prioritizing and Selecting Core International Crime Cases, Forum for International Criminal and Humantiarian Law, International Peace Research Institute (2009).

Zdzislaw Galicki (Sp. Rap.) Third Report on the Obligation to Extradite or Prosecute (aut dedere aut judicare), International Law Commission A/CN.4/603, 10 de junio de 2008.

\section{Artículos}

Arsanjani, Mahnoush, "The International Criminal Court and National Amnesty Laws", ASIL Proceedings, 1995.

Burke-White, William, "Reframing Impunity: Applying Liberal International Law Theory to an Analysis of Amnesty Legislation", Harvard International Law Journal, 2001, 42.

Cassel, Douglas, "Lessons from the Americas: Guidelines for International Response to Amnesties for Atrocities", Law \& Contemporary Problems, 1996, 59.

Cassese, Antonio, “The ICTY: A Living and Vital Reality”, Journal of International Criminal Justice, 2004, 2.

Dukic, Drazan, "Transitional Justice and the International Criminal Court - 'In the Interest of Justice?"', International Review of the Red Cross, 2007, 89.

Kress, Claus, "Reflections on the Iudicare Limb of the Grave Breaches Regime", 7 Journal of International Criminal Justice, 2009, 7.

Kress, Claus, "War Crimes Committed in Non-International Armed Conflicts and the Emerging System of International Criminal Justice", Israel Yearbook on Human Rights, 2000.

Olson, Laura M., "Provoking the Dragon on the Patio - Matters of Transitional Justice: Penal Repression v. Amnesties", International Review of the Red Cross, 2006, 88.

Orentlicher, Diane, "Settling Accounts: The Duty to Prosecute Human Rights Violations of a Prior Regime", Yale Law Journal, 1991, 100. 
Robinson, Darryl, "Serving the Interests of Justice: Amnesties, Truth Comissions, and the International Criminal Court", European Journal of International Law, 2003, 14.

Scharf, Michael, "The Amnesty Exception to the Jurisdiction of the International Criminal Court”, Cornell International Law Journal, 1997, 32.

Villa-Vicencio, Charles, "Why Perpetrators Should Not Always Be Prosecuted: Where the International Criminal Court and Truth Commissions Meet", Emory Law Journal, 2000, 49.

\section{Tratados}

Convenio de Ginebra para Aliviar la Suerte que Corren los Heridos y los

Enfermos de las Fuerzas Armadas en Campaña, 12 de agosto de 1949, 75 C.T.N.U. 31.

Convenio de Ginebra Relativo a la Protección Debida a las Personas Civiles en Tiempo de Guerra, 12 de agosto de 1949, 75 C.T.N.U. 287.

Convenio de Ginebra Relativo al Trato Debido a los Prisioneros de Guerra, 12 de agosto de 1949, 75 C.T.N.U. 135.

Convenio de Ginebra para Aliviar la Suerte que Corren los Heridos, los

Enfermos y los Náufragos de las Fuerzas Armadas en el Mar, 12 de agosto de 1949, 75 C.T.N.U 85.

Protocolo Adicional a los Convenios de Ginebra del 12 de agosto de 1949

Relativo a la Protección de las Víctimas de los Conflictos Armados

Internacionales, 8 de junio de 1977, 1125 C.T.N.U. 37.

Protocolo Adicional a los Convenios de Ginebra del 12 de agosto de 1949

Relativo a la Protección de las Víctimas de los Conflictos Armados Sin Carácter Internacional, 8 de junio de 1977, 1125 C.T.N.U. 609. 
